\title{
INVESTIGACIÓN/RESEARCH
}

Recibido: 11/07/2015 --- Aceptado: 01/09/2015 ---Publicado: 15/09/2015

\section{EL ANDAMIAJE RETÓRICO DE GÉNERO: UNA DELIBERACIÓN SOBRE LA CULTURA GENERIZADA DE LA UNIVERSIDAD AUTÓNOMA DE CIUDAD JUÁREZ, MÉXICO' ${ }^{1}$}

Clara Eugenia Rojas Blanco²: Universidad Autónoma de Ciudad Juárez, México. México crojas@uacj.mx

\section{RESUMEN}

En este artículo, presento una versión sumaria de una investigación amplia de corte cualitativo-interpretativa centrada en el análisis de la estructura simbólica de género en la Universidad Autónoma de Ciudad Juárez (UACJ), México. En esta versión, ofrezco una deliberación centrada en un análisis de la formación persuasiva/discursiva en donde examiné la relación entre retórica, poder y género a partir de los enfoques de la crítica feminista del discurso y la retórica contemporánea. En este caso, la tesis que guía mi deliberación es que la cultura generizada de la institución no permite la trasversalización de la perspectiva género, porque las

\footnotetext{
${ }^{1}$ Este artículo está relacionado con el libro: Rojas, C. E. (2015). Andamiaje retórico del género: Un conocimiento situado en la Universidad Autónoma de Ciudad Juárez (2010-2012), UACJ: México. (En prensa). Avances relacionados con esta investigación fueron presentados en: Primer Congreso de Investigadoras del SNI, celebrado los días 20 y 21 de noviembre 2014 en Puebla, México y en Congreso Nacional de la Asociación Latinoamericana de Estudios del Discurso, celebrado del 22 al 24 de abril 2015, en Mérida, Yucatán, México.
}

${ }^{2}$ Clara Eugenia Rojas Blanco: Doctora en Retórica y Comunicación con especialidad en Estudios de las Mujeres (New Mexico State University).

crojas@uacj.mx; claeurob@gmail.com 
creencias y prácticas androcéntricas en la institución no se reconocen, por los y las agentes de la comunidad universitaria, como prácticas sexistas. En este texto, ofrezco el resumen de un análisis de tropos realizado en corpus de entrevistas abiertas aplicadas a profesores/as de tiempo completo, en donde se cristaliza la normalización de la ideología de género en la institución. A partir de los hallazgos ofrezco la metáfora de "andamiaje retórico de género" para explicar un proceso socio-histórico complejo que enmarca la re/producción normalizada del género en la UACJ.

\title{
PALABRAS CLAVE
}

Cultura institucional de género - educación superior - crítica feminista - retórica ideología de género - Universidad Autónoma de Ciudad Juárez.

\section{THE GENDERED RHETORICAL SCAFFOLD: A DELIBERATION ABOUT THE INSTITUTIONAL GENDER CULTURE AT THE UNIVERSIDAD AUTÓNOMA DE CIUDAD JUAREZ, MEXICO}

\begin{abstract}
In this article, I present a succinct version of a comprehensive qualitative research project centered on the analysis of the gender symbolic structure in the Universidad Autónoma de Ciudad Juarez (UACJ), in Mexico. In this version, I offer a deliberation centered on the analysis of the persuasive / discursive formation, where I examined the relationship between rhetoric, power and gender from the approach of the feminist critique on discourse and contemporary rhetoric. In this case, the thesis that guides my discussion is that the gendered institutional culture does not allow the transversalization of the gender perspective, because the androcentric beliefs and practices within the university are not recognized, by the university agents (men and women), as sexist practices. In this text, I offer an analysis of a corpus of open-ended interviews, conducted with a group of full time professors from the UACJ where the normalization of the ideology of gender of the institution crystallizes. Based on my findings, I devised the "gender rhetorical scaffold" metaphor in order to explain the complex socio-historical process present in the re/production of gender within the UACJ.
\end{abstract}

\section{KEYWORDS}

Gender institutional culture - higher education - feminist critique - rhetorical criticism - gender ideology -Universidad Autónoma de Ciudad Juárez. 


\section{INTRODUCCIÓN}

En este artículo, presento una deliberación en torno a los tropos de género como andamios simbólicos y re-articulables de la cultura institucional de género de la Universidad Autónoma de Ciudad Juárez (UACJ). En este sentido, subyace el deseo de abrir un proceso de reflexión en torno a las implicaciones que ha tenido -- y tiene-para las mujeres y los hombres de la UACJ, a nivel personal y político, pensar la universidad a partir de una visión androcéntrica. Asimismo, este texto responde a mi interés, como académica feminista, de contribuir desde un conocimiento situado, en la UACJ y en Ciudad Juárez, a la conversación promovida por las reflexiones feministas interesadas en exponer, documentar y analizar la problemática de la cultura generizada de las Instituciones de Educación Superior (IES) en México (Palomar, 2004, 2011; Buquet, Cooper, Mingo \& Moreno, 2011; Munévar y Villaseñor 2005).

En este texto doy cuenta, principalmente, del lado afectivo de la cultura androcéntrica. Aunque no es un análisis de las emociones per se, el enfoque de la crítica feminista de la retórica da cuenta de la "retórica del conflicto moral" con el que se enfrentan las mujeres que confrontan al poder en una cultura androcéntrica, principalmente las feministas (Campbell, 2001: 198). Como eje central presento un análisis cualitativo-interpretativo en donde relato, a manera de marco contextual, un momento histórico en el que se produce una coyunturaque llamo "crisis de género", momento que me permite ver y escuchar la cultura generizada en la UACJ. Ese momento se perfila a finales del año 2009, cuando la administración en turno de la UACJ (2006-2012), se declara abiertamente interesada en buscar la certificación de la Equidad de Género promovida y otorgada por el Instituto Nacional de la Mujeres en México (INMUJERES). Paradójicamente, esta decisión coincide con el hecho de que en el año 2010, logré un financiamiento otorgado por el Consejo Nacional de Ciencia y Tecnología (CONACYT) para estudiar la cultura de género en la institución, en el que participaron tanto profesoras como alumnas de la institución.

El encuentro coyuntural de estos dos proyectos -uno oficial y uno feminista--produce una contradicción en donde me fue posible observar y documentar la reproducción y recreación del poder generizado, principalmente de manera simbólica. El ejercicio de este poder se encarnó en un grupo de agentes que representaban la jerarquía institucional, quienes "hablaron" primordialmente a través de la retórica del silencio. Esta retórica se conformó por un juego de metáforas de voz y silencio, en dónde éstas últimas funcionaron como caras de la misma moneda, constituyendo así un discurso sustentado en la minimización y exclusión. En este proceso, las investigadoras, de 
paso el proyecto, fuimos simbólicamente descalificadas, desdibujadas y desarticuladas del proyecto oficial.

A partir de los hallazgos, acuñé la metáfora de "andamiaje retórico de género" como una herramienta cualitativa útil para observar la estructura androcéntrica, profundamente normalizada que sólo se puede apreciar en momentos coyunturales. Así, en un tiempo, espacio o lugar específico se configura y comporta de una forma, en otro momento se desvanece y se re/articula de distinta manera. En este sentido, alude a la dificultad de nombrar y aterrizar los procesos discursivos que sostienen la presencia sutil, evasiva o ambigua del género como relación de poder simbólico. Su permanente re-articulación lo convierte en un poder resbaladizo y multifacético; es discursivo (en sentido amplio, no sólo lingüístico), pero en esa misma medida es performativo (Lazar, 2005; Scott, J. 2003; Hendricks \& Oliver, 1999; Butler, 1998, 1992; Austin, 1962). Así la retórica de la voz y el silencio estructura y sustenta la re/creación de lo que llamo andamiaje retórico de género.

Asimismo, yen este caso, entiendo el concepto de la retórica del silencio y la voz como un discurso persuasivo e intencional ejercido por quienes detentan el poder, como una retórica de menosprecio o práctica retórica significante hegemónica, que se sustenta en actos de devaluar, minimizar o borrar simbólicamente a quienes les resultan amenazantes o que considera inferiores, no dignos/as de su atención. En este sentido, la retórica del menosprecio se da como un acto de silencio autoritario que violenta, minimiza y justifica los actos de violencia de género como si no hubiese nada importante qué decir, qué ver, qué saber o qué hacer(Glenn, 1997; De Vault, 1999).

Considero que en todo proceso dialéctico se producen diversas situaciones retóricas (Biesecker, 1989; Code 1995) o procesos de deliberación pública, que cristalizan el sustento ideológico de las contradicciones, así como las tensiones y acciones de oposición que exponen, en este caso, los procesos de normalización del género. También se posibilitan las oportunidades para producir discursos contrahegemónicos. Una situación retórica puede -para bien o para mal- producir silencios que hablan y voces que silencian (xxxx, 2005, 2013). En esa tesitura, en situaciones de contradicción o crisis en las esferas públicas -siempre de por sí generizadas- es posible ver, escuchar y sentir cómo se encarna la estructura de género tanto en hombres, como en mujeres.

Siguiendo aGramsci (1985), una crisis o contradicción social (en este caso en la universidad como esfera pública) no es un evento extraordinario, sino parte de un proceso socio-histórico complejo que se manifiesta de diversas formas, lugares, tiempos y espacios, en donde los efectos y las causas se entrelazan, y no se puede establecer el punto de origen o incepción. El momento en que se visibiliza, sólo es una manifestación estridente que errónea y tendenciosamente se identifica como el origen. En este caso, la constitución socio-histórica de la cultura de género en la 
comunidad, se manifestó en la UACJ.Al igual que en otros momentos históricos vividos por las mujeres juarenses en su encuentro con el sistema patriarcal(e.g. el feminicidio), considero que la crisis de género en la UACJ, encarnó la normalización del sistema sexo-género como parte constitutiva de cultura institucional y se manifestó a través de las prácticas discursivas androcéntricas, en términos ontológicos y epistemológicos.

Aclaro, que si bien esta cultura no representa a todos los hombres en la universidad, todos tienen más posibilidad de ser favorecidos antes que las mujeres. La cultura androcéntrica siempre está articulada a otros sistemas de dominación como son, entre otros, el clasismo y el racismo. En este sentido, Connell (1995) argumenta que las instituciones están constituidas por la ideología de género. Dice que aun cuando el género no sea un aspecto sobresaliente en determinadas circunstancias, su presencia es tácita en el androcentrismo de muchas instituciones en donde no sólo los hombres, sino también las mujeres, son cómplices por medio de su participación habitual y diferenciada en sus comunidades de práctica particulares.

Inevitablemente, en este estudio subyace una trayectoria de vida no sólo como fronteriza/juarense, madre, académica y feminista, sino una activista comprometida con el cambio y transformación de las estructuras generizadas y de situación de "lo femenino y lo feminizado" en las mujeres, las niñas, niños y de otros históricamente afectados por esta estructura. Mi mirada está informada por la teoría crítica, por los feminismos de la diferencia, la mirada post-estructuralista, así como por mis reflexiones en torno a la expresión límite de la violencia de género en esta comunidad: El feminicidio.

\subsection{Consideraciones teóricas}

Las teorías feministas post-estructuralistas han contribuido de manera importante a la descripción/comprensión de la complejidad de los mecanismos discursivos que contribuyen en la re/producción de las la relaciones de poder de género en sistemas y contextos sociales específicos. En estos enfoques se reconoce que si bien la estructura del género, como sistema de dominación, sigue presente de manera explícita (violencia física, exclusión de las mujeres en espacios políticos, acoso sexual y la denigración pública de las mujeres, entre otras), en las sociedades contemporáneas se re/produce y refuerza de maneras más sutiles, que aparecen como formas de poder aparentemente inocentes, y son inminentemente discursivas o simbólicas (Lazar 2005; Wodak, 1997, 2008).

Como parte de esta conversación, mi deliberación se enmarca en los estudios feministas críticos de la retórica (rhetoricalcriticism) contemporánea que surgen a finales del siglo pasado (años 60’s y 70`s), y que son representativos de la pragmática estadunidense. En este marco, la retórica o discurso persuasivo se 
reconoce como acción simbólica sustentada por las relaciones de poder manifiestas en la materialidad de la retórica, la tropología y performatividad de la retórica y su relación con las prácticas socio-culturales. La crítica feminista de la retórica, tiene como punto de partida la re/valorización y re/conocimiento de las mujeres como agentes políticos capaces de hablar y escribir con voz propia en las esferas públicaspolíticas. Asimismo, plantean la necesidad de re/articular las tácticas y estrategias retóricas que históricamente han servido para sostener y justifican la cultura patriarcal (Foss, Foss\& Griffin 1999, Foss 1996, Condit 1997, Campbell 2001).

Estos estudios surgen en el contexto de la inestabilidad social y política de la lucha por la reivindicación de los derechos civiles estadunidenses, entre los que se encuentran: La lucha por la liberación de las mujeres, los movimientos de los y las chicanas, los y las africano-estadunidenses y la segregación racial, así como reclamos ambientalistas, los movimientos gay, protección a los animales, entre otros. Considero que entre las aportaciones más importantes de estos enfoques, es el estudio de la retórica como un proceso de comunicación humana y la posibilidad de de-construir el poder persuasivo del lenguaje a partir contextos socio-históricos específicos.

En este marco, el discurso retórico, o la retórica como se le llama comúnmente se entiende como una acción simbólica y como parte intrínseca de la comunicación humana. Es un discurso deliberado que tiene como característica primordial el uso de procesos discursivo-persuasivos y como contexto habitual los espacios públicos. Por eso ha sido y es parte ineludible de la construcción y la negociación de las relaciones de poder en toda interacción social. Históricamente se ha reconocido como demagogia o como discurso vacío. Los y las estudiosas de la retórica contemporánea lo reconocen como el brazo simbólico de los grupos hegemónicos para racionalizar o justificar su derecho a nombrar, asignar, excluir, torturar, invadir y empobrecer a vastos sectores de población en el mundo.

Al respecto, Blitzer (1998) argumentó que:

...la retórica política ha servido a buenos y malos propósitos, ha utilizado la inteligencia y la ha enfrentado; ha albergado los motivos más nobles, así como los más viles. Ha sustentado causas magnificas; pero también ha apoyado el reino de los déspotas y promovido mentiras y daños masivos" (p. 12). En ese tenor, Glenn (1997) afirmó que, "la retórica siempre inscribe la relación entre el lenguaje y el poder en un momento preciso incluyendo quién puede hablar, quién puede escuchar o quién acepta escuchar y qué se puede decir-aquellas mujeres que insisten en entrar a la arena retórica serán utilizadas, malinterpretadas y siempre ignoradas"(p. 2). Por tanto podemos afirmar que la retórica nunca es un discurso ornamental o vacío.

Por su parte, Karlyn Campbell (2001), precursora de los estudios feministas en la críticade la retórica, argumentó que la voz crítica en cuerpo de mujer que irrumpe en 
los espacios considerados tradicionalmente como "masculinos" (e,g. partidos políticos, espacios académicos, la iglesia ) de jure y de facto convierte a las mujeres en presencias transgresoras, incómodas, dentro y fuera de las instituciones, pues no se nos reconoce como sujetos históricos y agentes políticas. Ella expresó que, “desde sus inicios, el activismo feminista destapó tensiones entretejidas en lo profundo del imaginario social y produjo un discurso centrado en la "retórica del conflicto moral" (p. 128). Esto se debe, según la autora, a que contrario a otros grupos marginados, el estatus social de las mujeres se define desde su nacimiento, por tanto su subordinación se considera de orden natural. Así, la posición de las mujeres en la sociedad aparece siempre en contradicción con los valores fundamentales de la democracia.

En este orden de ideas, Cameron (2002) explicó que dentro de la crítica feminista del lenguaje, la voz y el silencio han sido metáforas muy poderosas que el discurso feminista ha utilizado de múltiples maneras para dilucidar los modos en que a las mujeres se les ha negado el derecho o la oportunidad de expresarse libremente. Concretamente, las metáforas de silencio y silenciamiento han significado la exclusión de las mujeres de la producción cultural y la ausencia de perspectivas basadas en las experiencias de las mujeres.

Al respecto, DeVault (1999) enfatizó que los enfoques feministas han centrado sus puntos de vista, principalmente, en la premisa de que, "las mujeres han sido silenciadas; y el feminismo se opone al silenciamiento de las mujeres" (178). Sin embargo, advirtió que estos enfoques resultan ya limitados, pues se deben analizar en detalle los contextos socioculturales en los que se dan los procesos, así como los mecanismos que los (re)producen. Explica que aunque la metáfora de silencio se refiere a una "ausencia" -- la ausencia de voz, en concreto del sonido del habla -- y que algunos usos feministas del término lo utilizan de manera cercana a este significado.

Además, la autora argumentó que otras teóricas feministas rebasan este significado estricto, tomando como punto de partida situaciones concretas en donde el no hablar, permanecer en silencio o no ser escuchadas se percibe como un proceso en donde pueden también puede significar,

...no estar presente, no participar o no escribir, hablar o escribir, pero no ser escuchada; hablar o escribir pero ser ignorada o ridiculizada; hablar o escribir sin aplomo o de manera afirmativa; hablar o escribir sin autenticidad; hablar o escribir de manera limitada acerca de ciertos temas, en ciertos lugares, tiempos y situaciones; o hablar o escribir de manera efímera o precaria (DeVault, p. 179).

En consecuencia, si entendemos el silencio exclusivamente en función de sus opuestos -- el habla, la voz y el ruido-- limitamos nuestra discusión en favor del habla o de la voz como factores únicos para la inclusión o la exclusión social. Necesariamente, discutimos la inclusión de la voz de las mujeres en el sentido 
estricto de vocalizar, hacer ruido $u$ otra especie de actitudes ruidosas. Asimismo, las estudiosas coinciden que no siempre la voz visibiliza y no siempre el silencio significa exclusión, por lo tanto debemos de repensar hacia dónde nos lleva este enfoque. Entonces, el silencio es una metáfora excelente para exponer qué pasa con las personas marginadas, también puede actuar como voz y convertirse en un acto de resistencia o de reflexión orientada a la praxis Glenn 2002; Rakow and Wackwitz, 2004; Clair 1998).

Así, en este marco y desde una perspectiva pragmática, el juego de tropos de la voz y el silencio se entienden como ideología o figuras de pensamiento que producen y recrean acciones simbólicas, que a sus vez re/produce y refuerza las prácticas sexistas. Estas acciones se redimensionan de tal forma que se representan en prácticas discursivas y materiales concretas, como son la exclusión, la estereotipación, la descalificación y descrédito, la condescendencia, entre otras, que impactan de manera sería el quehacer personal y laboral de las mujeres, en este caso en la UACJ.

\section{OBJETIVOS}

El objetivo general de la investigación amplia fue el analizar la cultura institucional con el fin de exponer, examinar y explicar de qué manera la cultura generizada de la UACJ limita o posibilita la transversalización de la perspectiva de género tanto dentro de la institución, así como en sus áreas de impacto. Como objetivos específicos, esbocé los siguientes: (a) analizar las acciones institucionales dirigidas a promover la transversalizacióndel enfoque de género en el marco del Plan de Desarrollo Institucional 2006-2012; (b) analizar la historia los artefactos, normas y valores que estructuran la cultura de género de la institución; y (c)en función de los hallazgos justificar un programa de postgrado en estudios de género. El objetivo específico de este texto, es presentar una versión sucinta de los hallazgos más sobresalientes de la investigación amplia.

Dada la cultura generizada de la institución, considero importante decir que siempre pensé que los objetivos se cumplirían en tiempo y forma, con sólo sistematizar de una manera consistente y transparente los datos obtenidos. El problema fue que si bien se logró aplicar las herramientas, siempre lo hicimos a contracorriente. La administración en turno promovió un discurso de descalificación hacia el proyecto, que retrasó el acceso no sólo a la información oficial, sino a realizar encuestas y entrevistas al personal, sobretodo administrativo. Fue hasta el finales del 2012, con una nueva administración (2012-2018) cuando fue posible avanzar en términos reales con el levantamiento de datos.

Al final, lo que resultó coyunturalmente muy útil para la investigación fue que el "género" estaba presente en el imaginario universitario. Para cuando se aplicaron las entrevistas abiertas, el comité institucional de género había ofrecido cursos de 
sensibilización de género y la Dirección General de Innovación Educativa había puesto en marcha el programa de materias sello por competencias, en las que se incorporó la enfoque de género y se instituyó un taller de género para los y las profesoras de reciente contratación como parte del modelo educativo.

\section{METODOLOGÍA}

El proceso metodológico de la investigación estuvo informado por los postulados de las epistemologías feministas, que exigen la reflexividad antes y durante en el proceso metodológico, no sólo en los aspectos técnicos, sino en cuanto a las implicaciones éticas entre el o la investigadora y las/os participantes. Si bien se hace hincapié en la característica situacional de gran parte de lo que se considera conocimiento, no se acepta el relativismo epistemológico. El aceptar el conocimiento como situado, no es lo mismo que afirmar que todas las perspectivas son válidas o "verdaderas". Lo que interesa en un conocimiento situado o situacional es que habilita preguntas específicas, sobre contextos específicos, y que son difíciles de enmarcar en epistemologías que consideran que el género, la afectividad, la subjetividad y la situación dela o el que conoce es irrelevante para el conocimiento (Harding, 2002; Alcoff, 1992; Alcoff \& Potter, 1993; Haraway, 1988 ).

En ese orden de ideas, el objetivo de la crítica feminista del discurso y la retórica busca explicar de qué manera la ideología y la performatividad de género construye (discursiva y materialmente) a las y los sujetos que saben en contextos situados. Entonces, se considera que quienes saben son portadoras de saberes situadas/os en relaciones particulares en relación con otros/sujetos epistémicos. Además, reconoce que la inequidad de género está intrínsecamente entrelazada con otros sistemas de inequidad. Por tanto, el objetivo central de toda investigación con enfoque de género tiene como propósitos centrales el desempacar los supuestos de género en las investigaciones sociales y humanísticas, en la vida cotidiana en general, así como develar cómo los supuestos centrales de género continúan organizando el mundo social (Harding, 2002; Alcoff, 1992; Alcoff \& Potter, 1993; Haraway, 1988 ). Sprague (2005) explicó que la investigación feminista con enfoque de género se sustenta en los siguientes postulados: (1) trabajar a partir del punto de partida de las y los que se encuentran en desventaja; (2) tomar en cuenta el privilegio y el poder en las experiencias e intereses; (3) mantener un discurso centrado en la multiplicidad de

posiciones del sujeto, y (4) construir conocimiento para beneficio de las o los que están en desventaja (75-79).

\subsection{Método y Herramientas}


El estudio se enmarcópor un enfoque cualitativo-interpretativo, toda vez que su objetivo tuvo como fin documentar procesos subjetivos de construcción de sentido desde un proceso inductivo, que no busca generalizar el conocimiento. El estudio expone un conocimiento situado en tiempo, lugar y espacio, que puede o no tener relación con otras experiencias en otros contextos de Educación Superior. Se utilizaron herramientas etnográficas como la observación participante, la bitácora y las entrevistas no-estructuradas, basadas en preguntas generadoras. Por ejemplo, entre las preguntas generadoras que se utilizaron para propiciar la conversación en torno a la relación entre género y sexismo estructuras fueron: ¿Qué significa para usted o cómo explicaría usted el género? ¿Eso significa que no hay (o si hay) sexismo en la universidad?

\subsection{Universo de estudio y participantes}

El grupo de 23académicas y 23académicos de tiempo completo, en su mayoría con grado doctoral. Las entrevistas se realizaron durante un período de dos años (20102012), para esta fechas se encuentra en proceso la certificación de género, pero a las y los académicos no se les había impartido ningún curso.

Se omiten los nombres propios, aunque sí es importante quién lo dice, en este caso utilizo seudónimos para proteger la privacidad de las entrevistadas/os, a través de los cuales marco la diferenciación por sexo. Las entrevistas se realizaron en los cuatro institutos del campus central de la UACJ.

\subsection{Corpus y unidad de análisis}

Analicé un corpus de 46 entrevistas no- estructuradas. El análisis tuvo como objetivo en documentar y analizar la construcción de sentido en torno a lo que significa el género y su relación con el sexismo. Como unidad de análisis tomé los tropos o formaciones ideológicas, relativas al género y sexismo. Una vez seleccionados los tropos, procedí a establecer la relación entre estos y el supuesto de la investigación.

\subsection{Género y sexismo}

Enseguida muestro algunos fragmentos textuales de las entrevistas realizadas, que ilustran de qué manera de algunos / as entrevistados/as, reconocen las prácticas sexistas, pero tiene un conocimiento limitado en ocasiones nulo de género. Por cuestiones de espacio, me centraré en las respuestas a dos preguntas que considero generadoras: ¿Qué significa el género? Si “todo somos iguales”, cómo explica que los puestos e mayor salario y toma de decisiones los ocupen sólo hombres? 
"Maricruz"(entrevista, abril 2012) afirma:

Mira yo creo que todos somos iguales aquí en la universidad. Yo al menos nunca me sentido discriminada por ser mujer, siempre me han respetado... Este, ¿te refieres a los techos de cristal? Si, mira yo creo que el que a las mujeres no se les invite o involucre para esos puestos tiene que ver con las relaciones laborales que hayan fomentado con los hombres que buscan esos puestos. Si eres una mujer inteligente y trabajadora, siempre te van a invitar. Tiene que ver con tus capacidades de realizar un trabajo, pero más que todo con ser política, ser diplomática, sería la palabra. Tú allí no ves, no oyes y no dices...pase lo que pase

"Pedro"(entrevista, octubre 2012) dice,

la igualdad de género si existe en la universidad. Lo podemos ver en que cada entran más mujeres a trabajar y a estudiar a la universidad. Yo creo que todos somos iguales en inteligencia y capacidad para hacer cualquier trabajo o estudios...pero el que las mujeres no ocupen esos puestos no tiene que ver con el sexismo, porque todos estos puestos administrativos no surgen de la nada. No... o sea surgen de una relación de amistades y de trabajo político muy fuerte, que requiere mucha confianza...son alianzas de grupo y entre grupos...si en su mayoría hombres...claro que participan mujeres, pero ya los puestos del núcleo nunca se han ocupado por mujeres...es allí donde ya no se confía en las mujeres...no sé por qué, pero es que entre el grupo centro hay otro tipo de compromisos...que incluso tienen que ver con relaciones por fuera de la universidad, como por ejemplo sus filias partidistas.

De acuerdo con "Pablo" (entrevista, junio 2011), el género tiene que ver con la discriminación de las mujeres. El afirma que:

Si tienen razón -las mujeres--no debe haber diferencias, porque somos iguales. No, no creo que eso -sólo hombres en la jerarquía-- sea sexismo, porque la confianza es un punto nodal en esa exclusión... ¡Uy! pues muchos son puestos de confianza, son puestos de confianza ¿no? y este la persona pues la pirámide va desde el rector, directores, y luego... ¿Cómo se dice?... los puestos de departamento, coordinadores ¿no?... entonces pues es una... una red de confianza ¿no?... el director le va a dar la oportunidad de ser el jefe de departamento a los que le tengan confianza en tanto personal como este, el trabajo administrativo ¿no? Entonces ya depende de allá [arriba]. No hay razón más que la confianza creo yo... o este como, como razón para que estén distribuidos así los puestos o sea porque digamos podemos decir que ahorita la persona que está dirigiendo el departamento, que está dirigiendo la 
universidad, es por credenciales y no hay mujeres con más credenciales que ellos mismos, y pues la única justificación que yo veo es la confianza.

"Elizabeth" (entrevista, noviembre 2012) explica que si bien el sexismo en la universidad existe, ya no es tan evidente como antes. Afirma que,

Aquí -en la universidad- si se practica el sexismo, muy veladamente, pero si hay una preferencia por elegir hombres para puestos claves de responsabilidades y salarios mayores. Esa es la historia de la universidad, siempre han sido hombres los que toman las decisiones y son hombres los que ocupan los puestos con mayor salario. Aquí ya no se da --pero si se daba-- el sexismo abiertamente, pero allí está, no como el que digan [los hombres] "no queremos que estén o no queremos trabajar con las mujeres"... así de evidente y tajante. Por ejemplo, a mí me invitaron en varias ocasiones para diversos puestos y pensaba éstos si son incluyentes...pero en las juntas y reuniones en la que se supone se toma decisiones...me daba cuenta que ellos ya se habían reunido por fuera [de la universidad] para tomar acuerdos, y en las reuniones siempre me "mayoriteaban"...Siempre éramos si acaso dos mujeres... tus opiniones no se toman en cuenta...ellos ya tiene una idea fija de que quieren para la universidad.

De manera similar, "Delia” (entrevista, febrero 2012), dice,

Cuando tienes tanto tiempo en este medio te das cuenta que es muy difícil que las mujeres podamos competir por puestos de dirección, porque, primero esos puestos se dan por amiguismo, no por méritos académicos, o por credenciales. Si como mujer tienes un amigo o amigos pues te invitan a que los apoyes...te acercan al poder, pero no te dan el poder de la toma de decisiones ...AH! y se te equivocas no es por la circunstancias, es porque eres mujer...siempre están sesgadas su opiniones de esa manera. Pero también las mujeres o muchas tienen que atender cosas de su familia como el esposo, los hijos y en general la casa. Cuando yo les pregunto por qué no aceptaron tal o cual puesto otras me han comentado que no les gustaría participar porque no quieren ser como los hombres... te encuentras con muchas razones pero la principal yo creo es que más allá de que te pagan un mejor salario, no te representa ninguna satisfacción personal, al contrario es muy desgastante.

"Gerardo" (entrevista, mayo 2011), argumenta que el sexismo en la universidad no existe y que las mujeres son incluidas en todo pero tienen que ser apoyadas por algún grupo. Mire yo no creo que sea por sexismo que las mujeres no ocupen puestos a ese nivel...eso se acabó hace tiempo en la Universidad...aquí no se discrimina a las mujeres...yo creo que tenemos muy buena convivencia. Bueno sí, sí hay sexismo, 
pero se da más de manera personal...hay hombre que son sexistas, pero no todos somos... las cosas en ese sentido de que las mujeres ocupen puestos se mueven de manera diferente. Desde siempre, aquí en la universidad la llegada a los puestos de dirección y a la rectoría, ha sido a través de los grupos... de grupos de apoyo, que apoyan a una x persona a llegar al poder...i si también con el objetivo de llegar ellos a la rectoría. Bueno sí, como usted dice grupos de poder... si usted no tiene un grupo que la apoye [como mujer] para que sea rector (sic) pues ni pensarlo...entonces pues las mujeres tienen que ser parte de ese grupo que está postulando para rector...Las mujeres tienen las mismas capacidades y algunas son más inteligentes que muchos que conozco, pero como le digo si no la apoyan de nada sirve.

"Lety" (entrevista , junio 2011) dice:

Fíjate a mí me dice un colega...es que las mujeres se quejan mucho cuando se les dan la comisiones...pero te imaginas! siempre esperan que tú hagas el aseo o el comidón para invitar a fulano o perengano...jAh! y entre ellos se perdonan todo...aparentemente porque después eso lo usan para atacarse políticamente... No deberás terminarás pensando y haciendo...como ellos. Mira, otra cosa, si hay una discusión ellos se gritan y hasta se insultan en general...y después como si nada. Pero si te hacen o te dicen algo a ti y tú les respondes o incluso les gritas entonces estás loca...o eres una histérica o una feminista.

De acuerdo con "Sandra" ( entrevista , mayo 2012) la discriminación hacia las mujeres en los nombramientos para obtener mayores apoyos o beneficios es cotidiana y que no se ve porque no les conviene verlo. Ella enfatiza que,

...es obvio que aunque ha habido mucho avance en que la mujer escale niveles más altos dentro de la institución, todavía no se da la oportunidad de la misma manera en que se da al sexo masculino, y si me ha tocado puros jefes hombres, y se ve muy marcado la diferencia que se tiene los del mismo género... entre ellos, entran y suben y escalan muy rápido y a las mujeres nos cuesta mucho...me ha tocado verlo infinidad de veces... un caballero que entra... por ejemplo tú haces hasta lo imposible por tener tus derechos y batallas, tienes que justificar y te piden hasta lo que no... para hacer valer tus derechos... y luego muchas veces con compañeros que no les cuesta mucho trabajo y con sólo negociar logran sus objetivos. Tristemente, pero así es...lo que pasa es que no lo queremos reconocer.

Según "Grisi" (entrevistas, junio 2012):

Sucede algo muy extraño, muy chistoso, no, muy chistoso no, algo como muy típico... ¿cómo llamarle?... más bien ofensivo. Me he dado cuenta de 
comentarios comunes que dice que los directores hombres que ejercen el poder tienen cierto honor, las mujeres que ejercen el poder son locas; son viejas locas, ya les da un ataque, o se ponen a gritar, o están histéricas. Esos son los comentarios que he escuchado de las mujeres y de los hombres. Si un hombre se sale de sus casillas y te trata muy mal, te gritonea $u$ ofende, es porque puede porque tiene poder. Si una mujer se sale sus casillas y te trata muy mal, es que está loca o te acusan de ser feminista histérica. O también dicen que "estás en tus días", sí eso me ha pasado, incluso, quizá inconscientemente, yo también lo he asimilado y las he tratado así; fulana está loca y fulanito, tiene poder.

\section{DISCUSIÓN}

A partir de mi experiencia como académica feminista, informada por conversaciones informales y las entrevistas con otras/os profesoras/ es puedo afirmar evidente que, como en cualquier cultura, la llamada cultura institucional de género de la UACJ, se re/produce y refuerza por medio de la constante negociación u oposición en la lucha, en este caso, no sólo por el sentido de lo que significa el género, también por los recursos económicos y simbólicos (los reconocimientos) otorgados por parte de la administración en turno. En este sentido, el avance de los cambios reales en términos cualitativos en la institución sólo son posibles si conviene a los intereses de la administración en turno, que a su vez responde a los intereses de los grupos de poder históricos de UACJ. Estos grupos han influido e influyen tanto de manera tácita como explícita en la producción y distribución de los bienes simbólicos y materiales de la institución.

Si bien, la presencia de las mujeres en la UACJ es cada vez mayor (como alumnas y como profesoras) y cada vez más mujeres ocupan posiciones en los puesto administrativos, los puestos de mayor jerarquía y mayor salario han estado y están ocupados por hombres. Es notoria la presencia de mujeres en los puestos de coordinación de carreras a nivel licenciatura, no así a nivel postgrado, así como en la administración central. Lo puesto ocupados por mujeres no sólo son los que requieren más trabajo, si no lo que tienen que ver con el trato directo con las y los alumnos y demás personal de la institución. La presencia de más mujeres en puestos administrativos no significa que la cultura androcéntrica haya cambiado. Significa que la mayoría de las mujeres, incluyendo las académicas, no cuestionan la jerarquía, ni la cultura androcéntrica. Con esto no quiero decir que no estén conscientes de que existe el sexismo en la universidad, sino que muchas lo racionalizan y negocian su posición en la estructura. Saben que oponerse o cuestionar la política sexista les puede colocar en posiciones de mayor desventaja, en muchas ocasiones son sujetas al ostracismo. 
Las autoridades en turno, promueven acciones simbólicas en las que favorecen a las mujeres que son "leales" o incondicionales del grupo de poder hegemónico en la institución y no en pocas ocasiones las enfrentan entre sí. Por ejemplo, como una primera acción hacia la certificación de género por INMUJERES, la administración en turno nombra a un grupo de mujeres, cercanas al grupo en el poder, como encargadas del comité institucional de género. En ningún momento se invitó o incluyó en la construcción de las políticas de certificación del género a quienes teníamos una trayectoria en el estudio de las reflexiones feministas. Todo lo contrario, en la primera reunión del comité institucional de género, y ante el cuestionamiento de algunas colegas por la ausencia de la mayoría de las estudiosas del género de la UACJ, la coordinadora del comité de género institucional expresó públicamente y de manera contundente lo siguiente: "No queremos trabajar con las feministas porque son muy problemáticas...no se puede trabajar con ellas..." (Comunicación personal. entrevista realizada el 6 de mayo 2011).

La estrategia de utilizar a un grupo de mujeres no-feministas como dispositivos de poder para silenciar simbólicamente a las feministas ha resultado muy efectiva para los grupos en el poder, en todos los ámbitos. En este sentido, cualquier controversia o reclamos sobre la ética, legitimidad académica o de trayectoria, se convertía metonímicamente, de jure y de facto, en un "problema entre mujeres", que alude al mito histórico de que las mujeres no podemos trabajar juntas. Esta estrategia deslegitima las voces y reflexiones feministas en muchos otros contextos.

Asimismo, cuando la UACJ promueve la certificación de Equidad de Género de la UACJ por parte Instituto Nacional de la Mujeres (INMUJERES), conformó un comité de género coordinado por una mujer en un puesto administrativo y por otras mujeres cercanas o partícipes directas del grupo de poder, en donde la mayoría no tenía ni idea que significa el género, más allá de una categoría descriptiva y sumatoria a la diferencia sexual. Esto produjo un discurso políticamente correcto en el que se promovió desde el inicio un discurso bajo el tropo de "Todos somos iguales", que tuvo como función homogeneizar metonímicamente en lo masculino las diferencias socioculturales entre hombres y mujeres.

Entonces, si "todos somos iguales", ¿de qué se quejan las feministas? Las académicas feministas - - y nuestra investigación - - fuimos objeto de un proceso discursivo sustentado por un discurso autoritario activado a través de la retórica del silencio representado como menosprecio. El tropo o figura de pensamiento de la "feminista problemática y odia hombres" es recurrente en las entrevistas realizadas tanto de hombres como de mujeres. En este sentido, la retórica del menosprecio funciona a través de descalificación y el descrédito al trabajo realizado por las especialistas en género de la institución. Evidentemente, este proceso de exclusión se basa en un discurso ad feminem (centrado en lo personal), un conocimiento limitado, y en 
ocasiones nulo, sobre las reflexiones feministas, principalmente en relación con el género.

Según "Verónica" (comunicación personal, noviembre 2012), el problema más grave estuvo en el hecho de ofrecer, como producto de la investigación, un programa de maestría en estudios de género. Ella dice:

Por bueno, urgente o necesario que fuese el programa...los programas académicos no pueden ser orgánicos en ninguna IES, por lo menos en México... su posible creación se acepta o se asigna desde arriba, y sólo a los grupos que son leales a la administración en turno... y menos una maestría conformada por feministas...fue muy ingenuo de su parte pensar que se iba a salir con la suya...el precio político va a ser alto.

Por su parte, “Juan" (comunicación personal, mayo 2012) comentó:

La orden de no apoyarte y desconocer tu trabajo venía de arriba...Pues de rectoría...del jefe y sus muchachos. Lo que yo he escuchado es que no quieren que avance el poder de las feministas en la UACJ...porque [se ríe] según algunos no obedecen, hacen lo que quieren, son muy autoritarias y agresivas...pero además, según algunos no se puede confiar en ustedes porque no respetan la lealtad de grupo.

Fue evidente que el problema no era incluir a "las mujeres" per se, sino incluir a "las feministas", aunque nos contemos con una mano. El temor central es que las feministas que "las feministas tengamos el poder" ; a las mujeres se les puede controlar a las feministas no. Aparentemente, un estudio realizado desde una perspectiva feminista era muy riesgoso para los grupos de poder en la institución, sobretodo porque las feministas entendemos el género como un sistema de opresión no sólo hacia las mujeres, también hacia los hombres. También se manifiesta una inquietud de que nuestro diagnóstico evidenciaría que la certificación de género era si no una simulación, si una acción que no pretendía cambios de fondo en la institución. Paradójicamente, INMUJERES contribuyó, intencionalmente o no, en el proceso de silenciamiento del pensamiento feminista en UACJ. Peor aún, el grupo oficial, con conocimientos incipientes o nulos de género representaron los estudios de género y de las mujeres de la UACJ, en diversos foros organizados a nivel nacional.

\section{CONCLUSIONES}

A lo largo de este texto muestro que la cultura generizada de la institución no permite la trasversalización de la perspectiva género, porque las creencias y prácticas androcéntricas en la institución no se reconocen, por los y las agentes de la comunidad universitaria, como prácticas sexistas. En primera instancia, y en 
función de los hallazgos confirmo que la cultura generizada en la UACJ se re/produce por hombres y mujeres desde muy diversas posiciones de sujeto, y que por muy diversas razones la racionalizan. Si bien la mayoría tienen un conocimiento limitado acerca de lo que significa "género", sí tienen bien claro que en la universidad se práctica el "sexismo". Con esto me refiero a que si sigue pensando que el problema de género, por una parte tiene que ver sólo con las discriminación hacia las mujeres, y por otro con un problema entre hombres y mujeres que requieren cambios a nivel individual o de pareja.

No reconocen que la re/producción de los discursos y prácticas sexistas se sostiene precisamente a través de una cultura de género que ha privilegiado históricamente la cultura androcéntrica, la visión, la historia, la ciencia, la experiencia y el quehacer de "lo masculino" en general, y en específico de los hombres que han ocupado u ocupan posiciones de poder. Estos hombres deciden y piensan por el resto desde una mirada unidimensional, parcial y sesgada, en el proceso de naturalizar su mirada como universal. Los grupos de poder históricos en la institución siempre han estado controlados por hombres, y también son la expresión de una cultura generizada. Son grupos que esperan la "lealtad" o el quehacer acrítico (que no cuestiones las relaciones de poder) de quienes deciden formar parte de éstos, ya sean hombres o mujeres. En este caso, se espera que las mujeres piensen y actúen como ellos, y generalmente vemos que así sucede.

En consecuencia, no se puede soslayar el hecho de que el silencio no siempre es impuesto o aceptado; así como es utilizado por los poderosos para borrar simbólicamente a otros/as, también puede ser un acto de resistencia. Aunque debemos aclarar, que para que el silencio funcione retóricamente como un acto de resistencia, el o la enunciadora debe ser reconocido como sujeto/agente; si no es así, da lo mismo que hable o no. En momentos de contradicción y crisis, tanto las voces como los silencios políticos adquieren múltiples y complejas dimensiones persuasivas o retórico-discursivas (e.g. estereotipos, identidades culturales, grafiti, arte urbano y narrativas, tropos, entre otras) que en un momento dado pueden producir o representar voces que silencian y silencios que enuncian, para bien o para mal.

Por tanto, el reconocimiento de las mujeres como agentes activos depende, en primera instancia, de la posibilidad y habilidad, por parte de las agentes involucradas, de articular, desarticular y re-articular el poder simbólico de la voz y el silencio utilizados como estrategias persuasivas para invisibilizarnos. Si las mujeres nos organizamos en grupos de poder dentro de la institución, se interpreta como un desacato a las reglas preestablecidas por todo un sistema de género y apuntalada discursivamente con los tropos de la las "feministas odia hombres". Este sistema contempla la inclusión subordinada de las mujeres, aunque ocupen puestos de dirección. 
Así la retórica de la voz y el silencio, de hombres y mujeres en la institución, estructura y sustenta la re/creación de lo que llamo "andamiaje retórico de género". En este sentido, alude también a la dificultad de nombrar y aterrizar los procesos discursivos que sostienen la presencia sutil, evasiva o ambigua del género como relación de poder simbólico. Su permanente re-articulación lo convierte en un poder resbaladizo y multifacético; es discursivo (en sentido amplio, no sólo lingüístico), pero en esa misma medida es performativo y su expresión más evidente se manifiesta en las actitudes y prácticas sexistas.

De acuerdo con los feminismos conocidos como liberales (Lorber, 2010) es necesario que las mujeres rompan el "techo de cristal" para que se pueda hablar/lograr la equidad de género en las instituciones u organizaciones. Esta afirmación no necesariamente es aceptada por otras miradas feministas, sobre todo aquéllas que afirman que el hecho de que las mujeres sean incluidas en las esferas de la toma de decisiones no cambiará la estructura generizada de las instituciones. En este sentido, Sandra Acker (2003) afirma que los puestos de poder ya están de por sí generizados, y que esto está implícito en la manera androcéntrica de organizar funciones y actividades. De esta manera, no todas las mujeres de la UACJ somos iguales, ni todas estamos dispuestas a participar la cultura institucional informada por el androcentrismo. En corto, no se trata de incluirse acríticamente a la estructura, se trata de cambiarla. Se trata de dar cabida a la diversidad de saberes, quehaceres y modos de ver y entender el mundo, tanto simbólico como material, que enriquezcan la cultura de la universidad.

\section{REFERENCIAS}

\section{Libros completos:}

Acker, J. (2003).Hierarchies, jobs, bodies: A theory of gendered organizations, In R. Ely, E. Foldy\& M. Scully (Eds.),Reader in Gender, Work, and Organization, Oxford: Blackwell Publishing.

Alcoff, L. (1992) The problem of speaking for others. Cultural Critique, 20 (4), 5-32.

Alcoff, L. and E. Potter (Eds.). (1993). Feminist epistemologies, New York: Routledge.

Austin, J.L. (1962).How to do things with words. Oxford: Oxford University Press.

Biesecker, B.(1989). Rethinking the rhetorical situation from within the thematic of difference. In J.Lucaites, C. Condit\& S. Caudill(Eds.). Contemporary rhetorical theory (pp. 232-246). New York: Guilford Press. 
Blitzer, L.( 1998). Political Rhetoric .In T. Farrell ( Ed.). Landmark essays in contemporary rhetoric (pp. 9-26). Hermagoras Press, New Jersey.

Butler, J. (1998). Actos performativos y constitución del género: un ensayo sobre fenomenología y teoría feminista. Debate Feminista, 9 (18) 296-314.

Butler, J. (1997) Excitable speech. Routledge: New York.

Campbell, K. (2001). The rhetoric of women's liberation: An oxymoron. In C. Morris III \& Stephen Browne(Eds.).Readings on the Rhetoric of Social Protest(pp.198211). Pennsylvania: Strata Publishing.

Cameron, D. (1998). The Feminist Critique of Language, London \& New York, Routledge.

Clair, R. (1998). Organizing silence. Albany:State University of New York Press

De Vault, M.(1999).Liberating method: feminism and social change.Philadelphia: Temple UP.

Code, L.(1995). Rhetorical spaces: essays on gendered locations. New York: Routledge.

Foss, S. (1996). Rhetorical criticism: exploration and practice. Prospect Hills: Waveland Press.

Foss, K.,S. Foss \&C. Griffin (1999). Feminist rhetorical theories.Thousand Oaks: Sage.

GlennC. (1997). Rhetoric retold. Carbondale \& Edwardsville: Southern Illinois University Press.

Gramsci, A. (1995). Selections from the Prison Notebooks. New York: International Publishers.

Hendricks, C. \& K. Oliver (Eds.). (1999). Language and liberation: Feminism, philosophy and language. Albany: State University of New York Press.

Lazar, M. (Ed.).(2005). Feminist critical discourse analysis.Gender, power and ideology in discourse, New York: Palgrave Macmillan.

Lorber, Judith (2010) Gender inequality.Feminist theories and politics (4th Ed.).New York: Oxford University Press.

Wodak, R. (Ed.). (1997). Gender and discourse (Sage Studies in Discourse), London:SAGE Publications.

\section{Artículos en papel y electrónicos:}

Buquet, A. et al. (2013). Intrusas en La Universidad. Universidad Nacional Autónoma de México, Programa Universitario de Estudios de Género. Disponible en: http:/ / www.academia.edu/8811934/Intrusas_en_la_universidad Consultado el 18/05/2013.

Condit, C. (1997). In Praise of Eloquent Diversity: Gender and Rhetoric as Public Persuasion, Women's Studies in Communication, 20,92-115.

Glenn, C. (2002). Silence: A rhetorical art for resisting discipline(s). JAC, 22 , 262- 289. 
Haraway, D. (1988).Situated knowledges: the science question in feminism and the privilege of partial perspective. Feminist Studies, (14) 575-599.

Harding, S. (1993). Rethinking standpoint epistemology. ¿ What is strong objectivity?

In L. Alcoff and E. Potter (Eds.) Feminist Epistemologies (pp. 10-35). New York: Routledge.

MunévarD.\&M. Villaseñor (2005).Transversalidad de género. Una estrategia para el uso político-educativo de sus saberes. En Revista de Estudios de Género La Ventana, (21), pp. 44-68.

Palomar C. (2005). La política de género en la educación superior, Revista de Estudios de Género. La Ventana, (21), pp.7-43.

Palomar C. (2011). La Cultura Institucional de Género en la Universidad de Guadalajara, México D.F.: ANUIES. Disponible: http://biblioteca.universia.net/html_bura/ficha/params/title/cultura institucional-genero-universidad-guadalajara-c-g-palomarverea/id/54599660.html

Consultado el 20 de septiembre 2013.

Rakow, L. \& and L. Wackwitz (Eds.).(2004). Feminist communication theory: selections in contexts. Thousand Oaks: Sage.

Sprague, J. (2005). Feminist methodologies for critical researchers.Bridging differences. The Gender Lens Series. Walnut Creek: AltaMiraPress.

Scott, J. W. (2003). El género una categoría útil para el análisis histórico. En M. Lamas (Ed.). El género la construcción cultural de la diferencia sexual. México: PUEG/UNAM.

Wodak, R. (2008). Introduction: discourse, text, and context. In R. Wodak\&M. Krzyzanowski (Eds.). Qualitative discourse analysis in the social sciences(pp.1-29), Basingstoke: Palgrave.

\section{Autora}

\section{Clara Eugenia Rojas Blanco}

Es Doctora en Retórica y Comunicación, con especialidad en Estudios de las Mujeres (New Mexico State University); Maestra en Estudios de la Comunicación, énfasis en Estudios Culturales(Universidad de Texas en El Paso). En actualidad se desempeña como profesora-investigadora en el Departamento de Humanidades de la Universidad Autónoma de Ciudad Juárez. Es representante del Cuerpo Académico: Discurso, Cultura y Género. Sus líneas de investigación son: (1) Retórica cultural, género y procesos de comunicación pública y política y (2) Discurso, poder y género. 